\title{
Determinan Kejadian Kanker Payudara Pada W anita Di Rsud Arifin Achmad Provinsi Riau Tahun 2019
}

\author{
Aulia Astri ${ }^{1}$, Syamsul Bahri Rivaí ${ }^{2}$, Sri Desfita ${ }^{3}$, Jasrida Yunita ${ }^{4}$, Nurlisis ${ }^{5}$ \\ ${ }^{1} \mathrm{M}$ ahasiswa Program Studi M agister Kesehatan M asyarakat STIKes $\mathrm{H}$ ang Tuah \\ 3,4,5STIKes Hang Tuah Pekanbaru \\ ¿U niversitas A bdurrab \\ Corespodence Email : aulia.astri12@gmail.com
}

\begin{abstract}
Breast cancer is among the most discussed cancers because of its malignancy which often ends in death. Based on the 2013 Basic Health Research Data (Riskesdas), the number of breast cancer patients reached 61,682 cases in Indonesia. As in Riau Province according to the medical records of A rifin A chmad Regional Hospital, breast cancer ranks first with 325 cases out of 580 cases in Irna Surgical Cendrawasih in 2016. Purpose of this study was to determine the determinants of breast cancer incidence in women in Arifin Achmad Regional Hospital in Riau Province in 2019. This research uses a quantitative research design with a case control approach. The research instrument used was a questionnaire. The sampling technique was Consecutive Sampling. This research was conducted in May to July 2019. Case samples in this study were women who were diagnosed positive for breast cancer and control samples were women who were diagnosed with negative breast cancer. Univariate and bivariate data analysis with chi square test and multivariate analysis using Simple Logistic Regression test. The results showed the most dominant variables related to cause and effect with the incidence of breast cancer were a history of abortion 3.7 times, a history of hormonal contraceptive use 5.4 times, the age of first child birth $>35$ years 3 times, and the number of nulliparous children 2.3 times. It is expected that health workers and related institutions will be able to provide health education regarding the positive and negative impacts of contraceptive use, the importance of planning the marriage age and promoting family planning programs that have been launched by the government.
\end{abstract}

Keywords: Breast Cancer, Age, History of A bortion, Hormonal Contraception, History of Breastfeeding, Age of Childbirth, Number of Children

\begin{abstract}
Abstrak
Kanker payudara termasuk kanker yang paling banyak diperbincangkan karena keganasannya yang sering kali berakhir dengan kematian. Berdasarkan Data Riset Kesehatan Dasar (Riskesdas) tahun 2013, jumlah penderita kanker payudara mencapai 61.682 kasus di Indonesia. A dapun di Provinsi Riau menurut catatan rekam medik RSUD A rifin Achmad, kanker payudara menempati urutan pertama dengan jumlah 325 kasus dari 580 kasus yang ada di Irna Surgical Cendrawasih pada tahun 2016. Tujuan penelitian ini yaitu untuk mengetahui determinan kejadian kanker payudara pada wanita di RSUD Arifin Achmad Provinsi Riau tahun 2019. Penelitian ini menggunakan desain penelitian kuantitatif dengan pendekatan case control. Instrumen penelitian yang digunakan adalah kuesioner. Teknik pengambilan sampel secara Consecutive Sampling. Penelitian ini dilakukan pada bulan Mei s/d juli 2019. Sampel kasus dalam penelitian ini wanita yang didiagnosis positif kanker payudara dan sampel control adalah wanita yang didiagnosisnegatif kanker payudara. Analisa data secara univariat dan bivariat dengan uji chi Square serta analisa multivariat dengan menggunakan uji Regresi Logistik Ganda. Hasil penelitian didapatkan variabel yang paling dominan berhubungan sebab akibat dengan kejadian kanker payudara adalah riwayat penggunaan alat kontrasepsi hormonal 5,4 kali dan dikontrol oleh riwayat abortus, usia melahirkan anak pertama > 35 tahun dan jumlah anak nullipara. Diharapkan kepada petugas kesehatan dan instansi terkait untuk dapat memberikan edukasi kesehatan mengenai dampak positif dan negative dalam pemakaian alat kontrasepsi, pentingnya merencanakan usia menikah dan menggiatkan program KB yang sudah dicanangkan pemerintah.
\end{abstract}

Kata kunci: Kanker Payudara, Riwayat A bortus, Kontrasepsi H ormonal, Usia M elahirkan, Jumlah Anak

Received: 30 N ov 2019, Accepted : 31 M ay 2020 - M ay 2020 - Jurnal Photon V ol.10 No.2

DOI : https://doi.org/10.37859/jp.v10i2.1631

PHOTON is licensed under a Creative Commons Attribution-ShareAlike 4.0 International License 


\section{Introduction}

Kanker payudara merupakan permasalahan wanita diseluruh dunia termasuk Indonesia yaitu 38 per 100.000 wanita. Globocan, International Agency for Research on Cancer (IARC) tahun 2012 dalam Kementerian Kesehatan RI tahun 2015, diketahui bahwa kanker payudara merupakan penyakit kanker dengan persentase kasus baru tertinggi yaitu $43,3 \%$ dan persentase kematian akibat kanker payudara sebesar 12,8\% (WHO, 2013). Kasus kanker payudara tersebar hampir di seluruh tempat pelayanan kesehatan terutama di rumah sakit. Berdasarkan Data Riset Kesehatan Dasar (Riskesdas) tahun 2013, jumlah penderita kanker payudara mencapai 61.682 kasus di Indonesia. Adapun di Provinsi Riau menurut catatan rekam medik RSUD Arifin Achmad, kanker payudara menempati urutan pertama dengan jumlah 325 kasus dari 580 kasus yang ada di Irna Surgical Cendrawasih pada tahun 2016. Diketahui jumlah kunjungan pasien yang mengidap kanker payudara pada tahun 2016 berjumlah 1286 kunjungan, mengalami kenaikan menjadi 2511 pada tahun 2017 dan mengalami penurunan menjadi 2495 pada tahun 2018.

Rumah Sakit Umum Daerah Arifin Achmad merupakan rumah sakit rujukan di Provinsi Riau. Pada tahun 2017, RSUD A rifin A chmad telah memiliki fasilitas pelayanan kanker khusus yaitu Instalasi Kanker Terpadu Seruni yang memiliki motto One Stop Service Cancer. Disana berbagai tindakan kanker dilakukan mulai dari pencegahan, pengobatan dan pemulihan serta ditangani oleh dokter spesialis dan sub spesialis di bidang kanker sehingga diharapkan akan dapat menurunkan angka kejadian dan kematian yang disebabkan oleh kanker (RSUD Arifin Achmad, 2017).

Penelitian tentang kanker payudara di RSUD A rifin Achamd juga pernah dilakukan oleh Titiana Yuswar pada tahun 2016 tentang Keterlambatan Pemeriksaan Kanker Payudara dan diperoleh hasil pengetahuan yang kurang beresiko 3 kali, pendapatan yang kurang beresiko 3 kali, jarak menuju empat pelayanan kesehatan yang jauh beresiko 2,5 kali, dan tidak merasakan sakit beresiko 2 kali lebih tinggi menyebabkan kanker payudara.

\section{The M ethod}

Penelitian ini bersifat kuantitatif analitik observasional dengan desain studi kasus kontrol. Sampel dalam penelitian ini menggunakan ketentuan jumlah minimal sampel tiap variabel yaitu 15 sampel. Sehingga jumlah sampel menjadi $15 \times 8=120$ orang. Dengan perbandingan sampel kasus dan kontrol 1:1 sehngga total sampel menjadi 240 orang. Teknik pengambiln sampel secara dengan Consecutive sampling.

\section{Result and Discussion \\ HASIL}

\section{Analisis Univariat}

$\mathrm{H}$ asil analisis univariat menunjukkan bahwa 45,0\% responden kasus memiliki usia yang berisiko, 15\% memiliki riwayat abortus,31,7\% memiliki riwayat penggunaan alat kontrasepsi hormonal, $13,3 \%$ responden $>5$ tahun penggunaan alat kontrasepsi hormonal, 42,5\% responden tidak memberikan ASI, $34,2 \%$ responden dengan lama memberikan <! Tahun, 33,3\% responden dengan jumlah anak nulipara.

Received: 30 N ov 2019, Accepted : 31 M ay 2020 - M ay 2020 - Jurnal Photon V ol.10 No.2

DOI : https://doi.org/10.37859/jp.v10i2.1631

PHOTON is licensed under a Creative Commons Attribution-ShareAlike 4.0 International License 
Analisis M ultivariat

Tabel 1 Analisis M ultivariat

\begin{tabular}{llcccc}
\hline No & \multicolumn{1}{c}{ Variabel } & $\begin{array}{c}P \\
\text { Value }\end{array}$ & OR & \multicolumn{2}{c}{$95 \% \mathrm{Cl}$} \\
& & & & Lower & Upper \\
\hline 1. & Riwayat A bortus & 0,008 & 3,765 & 1,414 & 10,025 \\
\hline 2. & Riwayat penggunaan alat kontrasepsi & 0,001 & 5,407 & 2,391 & 12,225 \\
\hline 3. & Usia melahirkan anak pertama & 0,001 & 3,091 & 1,620 & 5,895 \\
\hline 4. & Jumlah anak & 0,010 & 2,338 & 1,228 & 4,452 \\
\hline
\end{tabular}

\section{PEMBAHASAN}

1. Variabel yang Berhubungan dengan Kejadian Kanker Payudara

a. Riwayat A bortus

Dari hasil penelitian yang dilakukan, didapatkan bahwa terdapat hubungan yang signifikan antara riwayat abortus dengan kejadian kanker payudara pada wanita dengan $p$ value 0,008 $(\mathrm{OR}=3,765 \mathrm{Cl} 95 \%=1,414-10,025)$. $\mathrm{Hal}$ ini berarti responden yang memiliki riwayat abortus lebih beresiko 3,7 kali terhadap kejadian kanker payudara dibandingkan responden yang tidak memiliki riwayat abortus.

Penelitian yang dilakukan Bhadoria (2013) menyatakan adanya hubungan antara riwayat abortus dengan kejadian kanker payudara, diketahui wanita dengan riwayat abortus 6 kali lebih besar menderita kanker payudara. M engalami abortus/keguguran pada usia kandungan < 32 minggu akan menghambat proses pematangan payudara secara alami sehingga meningkatkan risiko kanker payudara. Selama kehamilan sampai usia < 32 minggu payudara mengalami perubahan jaringan. Perubahan jaringan tersebut menyebabkan payudara rentan terhadap zat karsinogen (Patrick, 2014)

Dari penelitian yang dilakukan di RSUD Arifin Achmad, wanita yang mengalami abortus adalah pasien yang cenderung melahirkan anak pertama pada usia di atas 35 tahun. Selain itu, pasien dengan riwayat abortus juga memiliki kecendrungan untuk tidak mempunyai anak kembali (nullipara) terutama wanita yang mengalami abortus pada kehamilan pertama. U paya promosi kesehatan sudah sering dilakukan oleh pemerintah terutama tentang gerakan hidup sehat dan ANC minimal 4x selama kehamilan. Namun masih banyak masyarakat yang enggan untuk datang ke pelayanan kesehatan dengan alasan jauh nya lokasi dan masih tingginya sosial budaya masyarakat di pedesaan terkait dukun kampung.

b. Hubungan Riwayat Penggunaan A lat Kontrasepsi H ormonal

Dari hasil penelitian yang dilakukan, didapatkan bahwa terdapat hubungan yang signifikan antara riwayat penggunaan alat kontrasepsi hormonal dengan kejadian kanker payudara pada wanita dengan $\mathrm{p}$ value $0,001(\mathrm{OR}=5,407 \mathrm{Cl} 95 \%=2,391-12,225)$. Hal ini berarti responden yang memiliki riwayat penggunaan alat kontrasepsi hormonal lebih beresiko 5,4 kali terhadap kejadian kanker payudara dibandingkan responden yang tidak memiliki riwayat penggunaan alat kontrasepsi hormonal. Penelitian yang dilakukan Prasetyowati (2014) menyatakan adanya hubungan antara riwayat penggunaan alat kontrasepsi hormonal dengan kejadian kanker payudara yaitu responden yang memiliki riwayat penggunaan kontrasepsi hormonal 3,3 kali lebih beresiko terhadap kejadian kanker payudara dibandingkan dengan responden yang tidak memiliki riwayat penggunaan alat kontrasepsi hormonal.

Received: 30 N ov 2019, Accepted : 31 M ay 2020 - M ay 2020 - Jurnal Photon V ol.10 N 0.2

DOI : https://doi.org/10.37859/jp.v10i2.1631

PHOTON is licensed under a Creative Commons Attribution-ShareAlike 4.0 International License 
M enurut Diananda (2017), penggunaan alat kontrasepsi hormonal yang berjenis pil dan suntik dalam jangka waktu yang lama memicu terjadinya kanker. Namun, pengaruh alat kontrasepsi hormonal dengan kanker payudara juga tergantung pada usia, lama pemakaian dan faktor lainnya. Dari hasil penelitian, responden menggunakan alat kontrasepsi hormonal dengan tujuan untuk menjarangkan kehamilan. M enurut asumsi peneliti, pilihan untuk menggunakan kontrasepsi hormonal dikarenakan alasan kecocokan dan dapat menjaga keseimbangan hormone estrogen dan progesterone sehingga jika ingin memiliki keturunan lagi tidak membutuhkan waktu lama untuk menyeimbangkan kedua hormone tersebut.

Selain itu, responden cendrung memilih alat kontrasepsi hormonal dikarenakan kemudahan untuk melakukan nya seperti pil yang diminum seperti obat atau suntik yang di lakukan sekali sebulan. Responden megatakan enggan menggunakan kontrasepsi non hormonal seperti IUD dikarenakan alasan takut dan malu untuk melakukan pemasangan alat KB tersebut dan jika menggunakan kondom banyak suami yang menolak dengan alasan wanita yang seharusnya ber KB. Lembaga terkait seperti BKKBN sudah gencar melakukan promosi KB dan masyarakat juga sudah mulai menyadari akan penting nya ber $\mathrm{KB}$. $\mathrm{N}$ amun menurut asumsi peneliti, masih kurangnya informasi mengenai jenis alat-alat kontrasepsi yang di gunakan serta proses dan dampak positif negative yang akan diterima oleh pasien jika menggunakan alat kontrasepsi tertentu bagi masyarakat di daerah-daerah pedesaan.

$\mathrm{Hal}$ ini juga terkait dengan jumlah tenaga kesehatan yang minim dan sarana prasarana kesehatan yang masih kurang. Salah satu solusi yang ditawarkan yaitu dengan meningkatkan jumlah tenaga kesehatan di daerah pedesaan dan sarana prasarana penunjang KB serta lebih menggiatkan promosi KB terutama kepada para suami sehingga meningkatkan minat suami untuk ikut serta dalam program KB tersebut.

C. Hubungan Usia melahirkan anak

Dari hasil penelitian yang dilakukan, didapatkan bahwa terdapat hubungan yang signifikan antara usia melahirkan anak pertama dengan kejadian kanker payudara pada wanita dengan $\mathrm{p}$ value $0,001(\mathrm{OR}=3,091 \mathrm{Cl} 95 \%=1,620-5,895)$. Hal ini berarti responden dengan usia melahirkan anak pertama $>35$ tahun lebih beresiko 3 kali terhadap kejadian kanker payudara dibandingkan responden dengan usia melahirkan anak pertama $<35$ tahun.

Hasil penelitian sejalan dengan hasil penelitian Amrieds (2016) yang menyatakan adanya hubungan antara usia melahirkan anak pertama dengan kejadian kanker payudara. menurut Nurcahyo (2010), payudara seseorang mengalami perkembangan dan juga kemunduran sesuai umurnya. Wanita memiliki usia efektif untuk hamil dan menghasilkan ASI pada usia 20-35 tahun. Kehamilan pertama yang dialami pada usia yang sudah tidak efektif sangat berpotensi memunculkan kelainan sel di dalam payudara. $\mathrm{H}$ al ini juga berlaku pada kehamilan dibawah 20 tahun.

Selain itu penelitian yang dilakukan oleh Desiyani di Rumah Sakit Pertamina Cilacap juga diperoleh hasil terdapat hubungan yang signifikan antara usia pertama kali melahirkan dengan kejadian kanker payudara dengan $\mathrm{p}$ value 0,0085. Menurut asumsi peneliti, perubahan payudara selama kehamilan mungkin memiliki efek perlindungan terhadap terjadinya kanker karena resiko kanker payudara digambarkan menurun setiap penambahan kelahiran. Oleh karena itu, semakin lambat umur seseorang untuk melahirkan anak pertamanya, maka level eksposur estrogen dalam dirinya semakin tinggi.

d. Hubungan Jumlah Anak

Received: 30 N ov 2019, Accepted : 31 M ay 2020 - M ay 2020 - Jurnal Photon V ol.10 N 0.2

DOI : https://doi.org/10.37859/jp.v10i2.1631

PHOTON is licensed under a Creative Commons Attribution-ShareAlike 4.0 International License 
Dari hasil penelitian yang dilakukan, didapatkan bahwa terdapat hubungan yang signifikan antara jumlah anak dengan kejadian kanker payudara pada wanita dengan $p$ value 0,010 $(\mathrm{OR}=2,338 \mathrm{Cl} 95 \%=1,228-4,452)$. $\mathrm{Hal}$ ini berarti responden dengan jumlah anak nullipara lebih beresiko 2,3 kali terhadap kejadian kanker payudara dibandingkan responden dengan jumlah anak multipara.

Hasil penelitian Prihatin (2013) menyatakan adanya hubungan antara jumlah anak dengan kejadian kanker payudara. Menurut Rasjidi (2009), mengemukakan wanita nulipara mempunyai risiko $30 \%$ untuk berkembang menjadi kanker dibandingkan dengan wanita yang multipara. Hasil penelitian ini juga sejalan dengan penelitian yang dilakukan oleh Ardiana yang menyatakan bahwa faktor paritas memiliki hubungan yang paling bermakna terhadap kejadian kanker payudara dengan besar $\mathrm{OR}=6,38$. Berdasarkan penelitian yang dilakukan, responden yang nullipara sebenarnya ingin memiliki keturunan namun pernah mengalami abortus dan atau belum pernah hamil sama sekali. Salah satu upaya yang dapat dilakukan seperti pencegahan abortus melalui edukasi dan ANC rutin serta informasi mengenai penanganan infertilitas kepada pasangan yang tidak memiliki keturunan.

\section{KESIM PULAN}

Variabel yang mempunyai hubungan sebab akibat yaitu riwayat abortus, riwayat penggunaan alat kontrasepsi, usia melahirkan anak pertama dan jumlah anak terhadap kejadian kanker payudara pada wanita di RSU D A rifin A chmad Provinsi Riau tahun 2019.

\section{SARAN}

A dapun saran kepada petugas kesehatan untuk memberikan edukasi kesehatan kepada wanita mengenai dampak negative dan positif dalam penggunaan jenis-jenis alat kontrasepsi, kepada keluarga untuk bersikap proaktif dalam mengingatkan dan memperhatikan asupan nutrisi bagi wanita yang sedang dalam masa kehamilan atau mendukung wanita untuk memeriksakan payudara sendiri dari usia 20 tahun, Mammografi yang dilakukan mulai usia 40-49 tahun secara berkala. Adapun bagi petugas kesehatan baik di Puskesmas maupun di Rumah Sakit untuk menggiatkan upaya KIE terkait kanker payudara berikut upaya pencegahannya.

\section{References}

American Cancer Society. (2015). Breast Cancer Facts \& Figures 2015-2016. Retrieved from http://cancer.org/acs/groups/content.

Anggorowati. (2013). Faktor Risiko Payudara Wanita. Jurnal Kesehatan Masyarakat, (ISSN 1858-1196). Retrieved from https://journal.unnes.ac.id

Ariani, Ni Gusti, P.K., Ida, B. T. . (2018). Faktor Risiko Paparan Hormon Reproduksi Wanita Pada Penderita Kanker Payudara di Rumah Sakit Umum Pusat (RSUP) Sanglah Denpasar. E Jurnal M edika, 7. Retrieved from https://ojs.unud.ac.id

H asdianah, H.R., Sentot, I. . (2014). Patologi dan Patofisiologi Penyakit. Yogyakarta: N uha M edika.

Haslinda, E.K, S. (2013). Faktor Risiko Kejadian Kanker Payudara di RSUP DR. W ahidin Sudirohusodo $M$ akassar. Retrieved from http://ejournal.stikesnh.ac.id/

Hikmanti, A., Fauziah, H. N. . (2014). Analisis Faktor-Faktor yang Mempengaruhi Keterlambatan Pengobatan Pada W anita Penderita Kanker Payudara. Retrieved from https://jurnal.unimus.ac.id

Irawan, E. . (2017). Hubungan Antara Usia M enarche dan Riwayat Keluarga dengan Kejadian Kanker Payudara Pada Wanita Usia 35-60 Tahun di Ruang Kemoterapi RSUD Panembahan Senopati Yogyakarta Bantul. Retrieved from http://elibrary.almaata.ac.id

Received: 30 N ov 2019, Accepted : 31 M ay 2020 - M ay 2020 - Jurnal Photon V ol.10 No.2

DOI : https://doi.org/10.37859/jp.v10i2.1631

PHOTON is licensed under a Creative Commons Attribution-ShareAlike 4.0 International License 
Kementerian Kesehatan Republik Indonesia. (2015). Pusat Data dan Informasi. Jakarta: Kementerian Kesehatan RI.

Listyawati. (2015). Hubungan Riwayat M enyusui dengan Kejadian Kanker Payudara di Rumah Sakit U mum Daerah M untilan. Retrieved from http://digilib.unisayogya.ac.id

M ulyani, S.M , M ega, R. (2013). Kanker Payudara dan PM S Pada Kehamilan. Yogyakarta: N uha M edika.

Mulyasari, A.D., Hartati,B., Cece, S. . (2017). Analisis Faktor Risiko Kanker Payudara pada RSU.

BahteraM as Kota Kendari Provinsi Sulawesi Tenggara Tahun 2017. Jurnal IImiah Mahasiswa

Kesehatan M asyarakat, 2. Retrieved from https://jurnal.unimus.ac.id

Nani, D. (2009). A nalisis Faktor-faktor yang Berhubungan dengan Kejadian Kanker Payudara di Rumah

Sakit Pertamina Cilacap. Jurnal Keperawatan Soedirman. 4. Retrieved from http://jks.fikes.unsoed.ac.id

N otoatmodjo. (2012). Promosi Kesehatan dan Perilaku Kesehatan. Jakarta: RINEKA CIPTA.

Nugroho, T. (2011). ASI dan Tumor Payudara. Yogyakarta: Nuha M edika.

Nurcahyo, J. (2010). A was!!! Bahaya Kanker Rahim dan Kanker Payudara. Yogyakarta: W ahana Totalita Publisher.

Nurhayati. (n.d.). Faktor-Faktor Risiko Yang Berhubungan Dengan Kejadian Kanker Payudara Di Rumah Sakit Umum Daerah Kota Padangsidimpuan Tahun 2016. Retrieved from http://jks.fikes.unsoed.ac.id

Nurwijaya, H., Andrijono, S. (2010). Cegah dan Deteksi Kanker Serviks. Jakarta: PT. Elex Media Komputindo.

Oktaviana, D. . (2011). Faktor-Faktor Risiko Kanker Payudara Pada Pasien Kanker Payudara W anita di Rumah Sakit Kanker D harmais Jakarta. Jurnal U SU. Retrieved from https://jurnal.usu.ac.id

Prabandari, F., Dyah, F. (2016). Faktor-Faktor Yang M empengaruhi Kejadian Kanker Payudara Di RSU Dadi Keluarga Purwokerto. A kademi Kebidanan YLPP Purwokerto. Jurnal IImiah Kebidanan, 7. Retrieved from https://ejurnal.poltekkes-tjk.ac.id

Prasetyowati., K. . (2014). Faktor-Faktor yang Berhubungan dengan Kejadian Kanker Payudara di RSUD DR. H. Abdul Moeloek Provinsi Lampung. Jurnal Kesehatan M etro Sai Wawai, 2. Retrieved from https://ejurnal.poltekkes-tjk.ac.id

Priyatin, C., Elisa, U., Sri, S. (2013). Faktor Risiko yang Berpengaruh Terhadap kejadian Kanker Payudara di RSU P DR. Kariadi Semarang. Jurnal Kebidanan, 2.

Rianti, E., Gusti, A.T., Henny, N. (2012). Faktor-Faktor yang Berhubungan dengan Risiko Kanker Payudara W anita. Jurnal $\mathrm{H}$ ealth Q uality, 3. Retrieved from https://www.poltekkesjakartal.ac.id

Suciawati, A. (2015). Faktor-Faktor Yang Berhubungan Dengan Kejadian Kanker Payudara Di Wilayah Rumah Sakit Umum Kabupaten Tangerang Provinsi Banten Tahun 2015. Jurnal Akademi Keperawatan H usada Karya Jaya, 3. Retrieved from http://ejurnal. husadakaryajaya.ac.id

Sulung, N e., Rizki, Y, A. (n.d.). Determinan Kejadian Ca M ammae Di Poli Rawat Jalan Bedah RSUD DR. Achmad M ochtar. ST IK es Fort De K ock Bukittinggi. Jurnal Endurance, 3.

Yulianti, I., Herry, S, Dwi, S. (2016). Faktor-Faktor Risiko Kanker Payudara. Fakultas Kesehatan M asyarakat U niversitas Diponegoro. Jurnal Kesehatan M asyarakat, 4.

W HO . (2013). Risk Factor of M amae Cancer.

Received: 30 N ov 2019, Accepted : 31 M ay 2020 - M ay 2020 - Jurnal Photon V ol.10 No.2

DOI : https://doi.org/10.37859/jp.v10i2.1631

PHOTON is licensed under a Creative Commons Attribution-ShareAlike 4.0 International License 